\title{
Images in \\ Cardiovascular Medicine \\ A Long Journey to the Truth: Primary Cardiac Lymphoma with Various Arrhythmias from Ventricular Tachycardia to Atrial Flutter
}

\section{OPEN ACCESS}

Received: Sep 19, 2019

Revised: Nov 11, 2019

Accepted: Nov 26, 2019

Correspondence to Yong-Seog Oh, MD, PhD

Division of Cardiology, Department of Internal Medicine, Seoul St. Mary's Hospital, College of Medicine, The Catholic University of Korea, 222, Banpo-daero, Seocho-gu, Seoul 06591, Korea.

E-mail: oys@catholic.ac.kr

*Sunhwa Kim and Yoo Ri Kim contributed equally to this work.

Copyright (c) 2020. The Korean Society of Cardiology

This is an Open Access article distributed under the terms of the Creative Commons Attribution Non-Commercial License (https:// creativecommons.org/licenses/by-nc/4.0) which permits unrestricted noncommercial use, distribution, and reproduction in any medium, provided the original work is properly cited.

ORCID iDs

Sunhwa Kim (D)

https://orcid.org/0000-0003-3109-9210 Yoo Ri Kim (1D)

https://orcid.org/0000-0001-7351-1299 Young Choi (iD)

https://orcid.org/0000-0003-3900-1943

Sung-Hwan Kim (D)

https://orcid.org/0000-0001-6805-0416

Yong-Seog Oh (iD

https://orcid.org/0000-0003-3567-6505

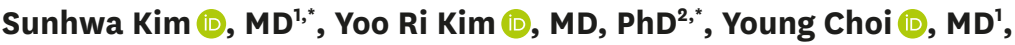

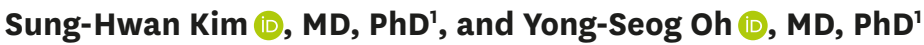

'Division of Cardiology, Department of Internal Medicine, Seoul St. Mary's Hospital, College of Medicine, The Catholic University of Korea, Seoul, Korea

${ }^{2}$ Division of Cardiology, Department of Internal Medicine, Dongguk University Ilsan Hospital, Goyang, Korea

On May 11, 2010, a 43-year-old man visited our hospital with palpitations and dizziness for one year. Initial electrocardiogram (ECG) showed first and second degree atrioventricular block (Figure 1A and B). At first, transthoracic echocardiogram (TTE) was normal (Figure 2A). Over a 7-year period, ECG findings gradually proceeded and various arrhythmias developed including ventricular tachycardia (VT) (Figure 1C-F). TTE showed diffuse progressive ventricular and atrial wall thickening (Figure 2B and C). Finally, TTE expressed a huge mass in right atrial cavity (Figure 2D). A total of 3 transvenous endomyocardial biopsies were performed and all revealed no abnormal findings. Chest computed tomography (CT) showed huge cardiac masses and anterior mediastinal lymph node enlargement (Figure 3). He was initially considered as hypertrophic cardiomyopathy and then cardiac sarcoidosis. On April 5, 2017, anterior mediastinal lymph node excision biopsy was conducted and the pathology was malignant large B cell lymphoma (Figure 4). He was finally diagnosed with primary cardiac lymphoma (PCL). Rituximab, cyclophosphamide, doxorubicin, vincristine, and prednisolone chemotherapy was performed. On positron emission tomography-CT after 9 months of chemotherapy, ${ }^{18} \mathrm{~F}$-fluorodeoxyglucose uptake significantly decreased (Figure 5) and VT no longer occurred. TTE findings became almost normal (Figure 2E).

PCL is a rare disease composing $1.3 \%$ of primary cardiac tumors. ${ }^{1)}$ PCL has no pathognomonic presentation, manifested by location. Intramural tumors can present with fatal arrhythmia such as VT or conduction defects ${ }^{2-4)}$ at the beginning by invading the conduction system even before the structural lesion is detected. Continuous questions of VT mechanism and constant biopsies finally reached the proper diagnosis. And active treatment of intractable VT with amiodarone, implantable cardiac defibrillator and radiofrequency catheter ablation prevented death of the patient.

The informed consent that allows the publication of clinical data was obtained from the patient. 
(A)

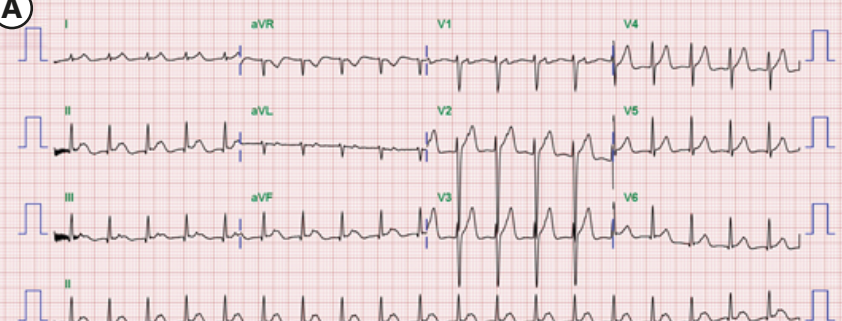

(C)

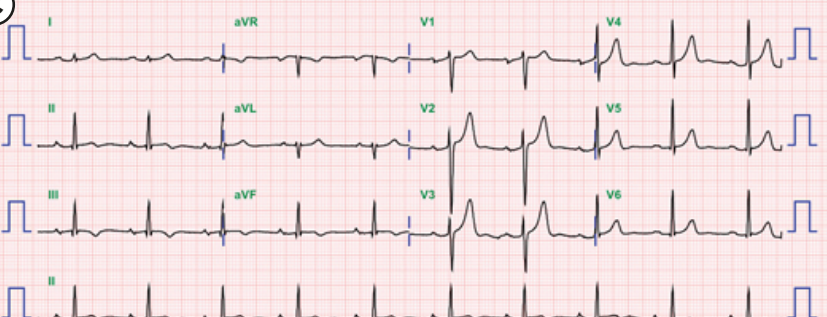

E)

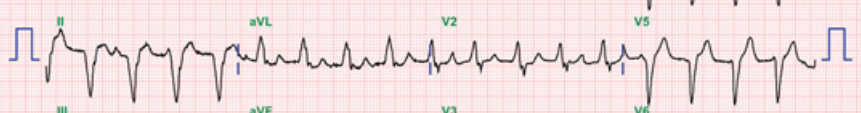

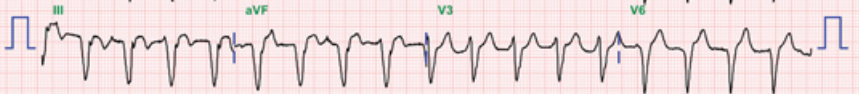

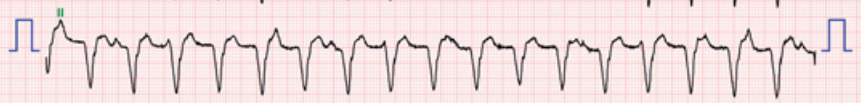

(B)

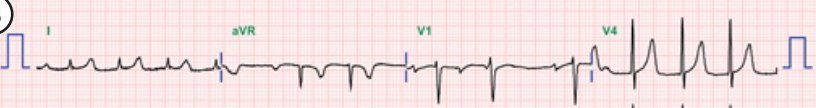

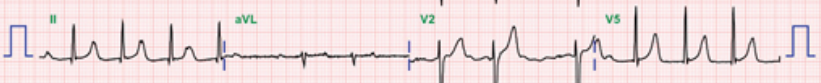

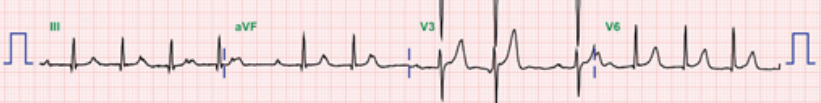

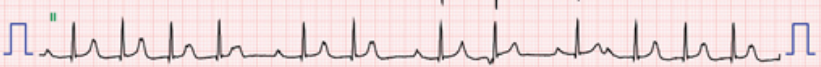

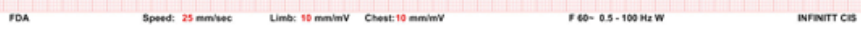
(D) $\Omega$ III $^{\prime \prime 2}$

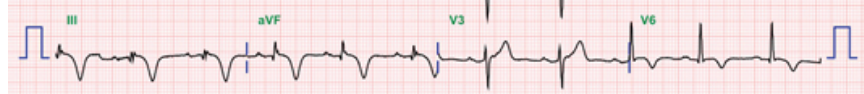

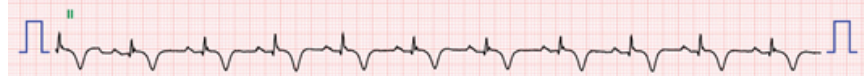

Figure 1. Twelve-lead ECGs. (A) ECG at the time of the first hospital visit showed 1st degree AV block (PR interval $360 \mathrm{ms).} \mathrm{(B)} \mathrm{Mobitz} \mathrm{type} \mathrm{I} \mathrm{second-degree}$ AV block was also recorded. (C) In the 3rd year after the first visit, T inversion began to be observed. (D) In the 4th year after the first visit, deep T-inversion proceeded in inferior leads and lateral precordial leads. (E) In the 5th year after the first visit, intractable ventricular tachycardia developed. (F) In the 7th year, after steroid pulse therapy for sarcoidosis, a typical atrial flutter occurred.

$\mathrm{AV}=$ atrioventricular; $\mathrm{ECG}=$ electrocardiogram.

Conflict of Interest

The authors have no financial conflicts of

interest.

\section{Author Contributions}

Supervision: Choi Y, Oh YS, Kim SH; Writing -

original draft: Kim S; Writing - review \& editing:

Kim YR. 

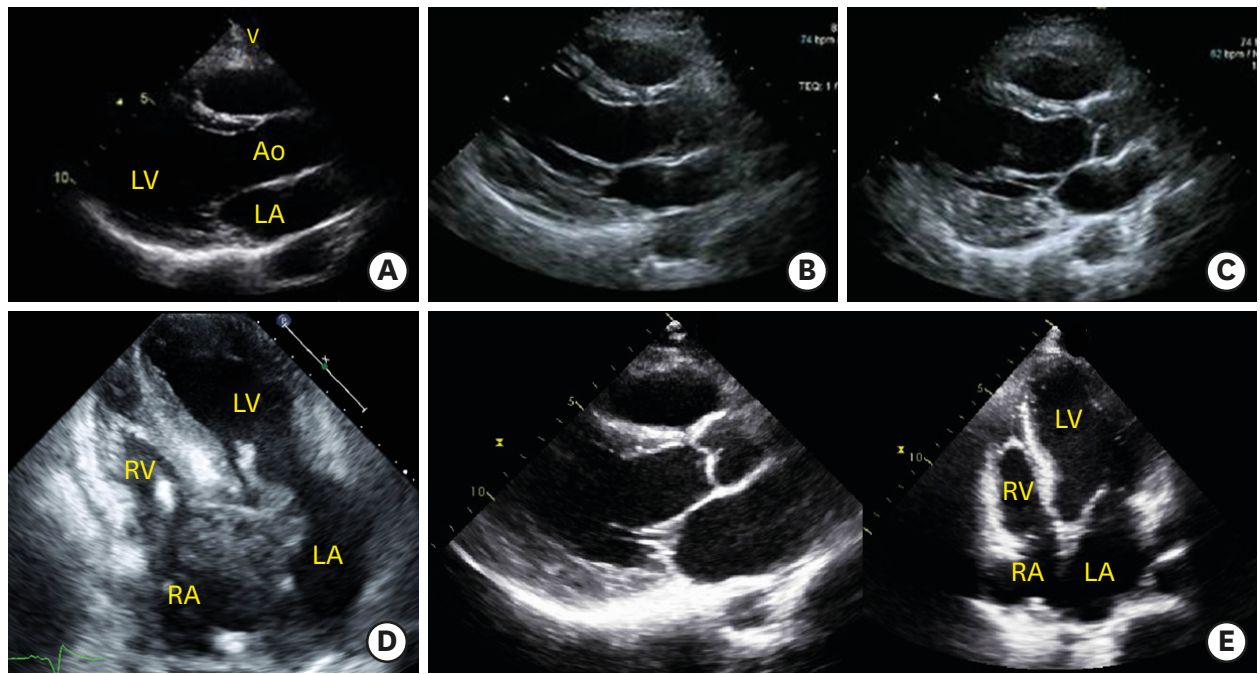

Figure 2. Images of transthoracic echocardiography. (A) Transthoracic echocardiogram at the time of the first hospital visit showed normal findings. (B) In the 4th year after the first visit, it indicated hypertrophied posterior wall thickness with hyperechoic myocardium. (C) In the 5th year after the first visit, unusual pattern of LV inferolateral wall hypertrophy was shown. (D) In the 7th year after the first visit, more progression of asymmetric LV hypertrophy and a huge mass in RA cavity with near-total obstruction of flow across tricuspid valve were observed. (E) Nine months after chemotherapy, the huge mass involving interatrial septum disappeared and LV wall thickness was nearly normalized.

$\mathrm{Ao}=$ aorta; $\mathrm{LA}=$ left atrial; $\mathrm{LV}=$ left ventricular; $\mathrm{RA}=$ right atrial; $\mathrm{RV}=$ right ventricular .

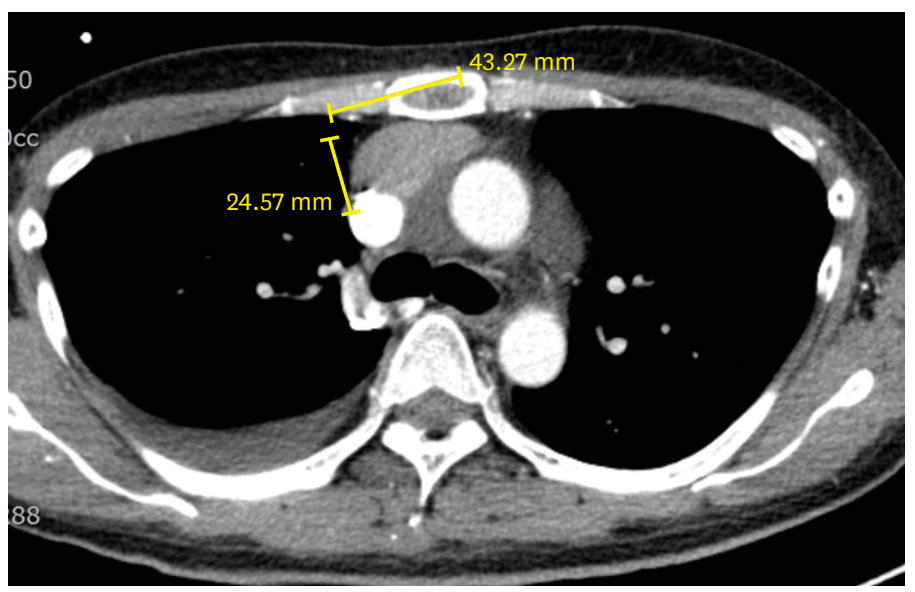

Figure 3. Chest computed tomography in the 7th year after the first hospital visit revealed anterior mediastinal lymph node enlargement. 


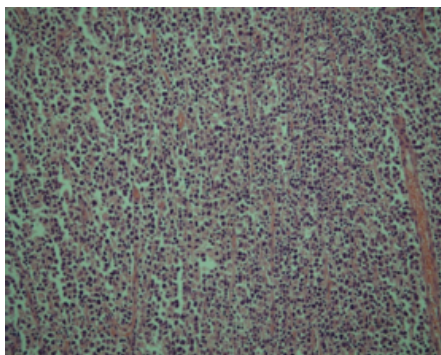

[ IHAWNOHISTOCHEMISTRY]

(pha-fetoprotein

$1+17-002950$

$1417-0002950$

IH17-002950

IH17-002950

IH17-002950

IH17-003020

IH17-003020

IH17-003020

IH17-003020

$1 \mathrm{H17}-003020$

14t7-

IH17-003020

alpha-f
003
0020

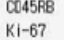

Pencytokerat in

BC12

BC12
BC16
Co10

$\infty 223$

co30

Mox-1
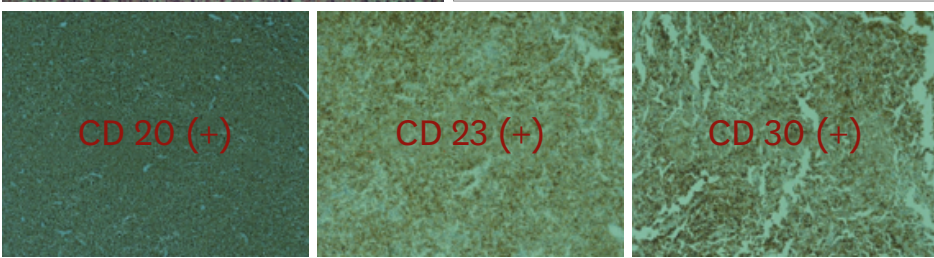

[Diagnosis]

Malignant lymphoma, mediastinal large B cell lymphoma
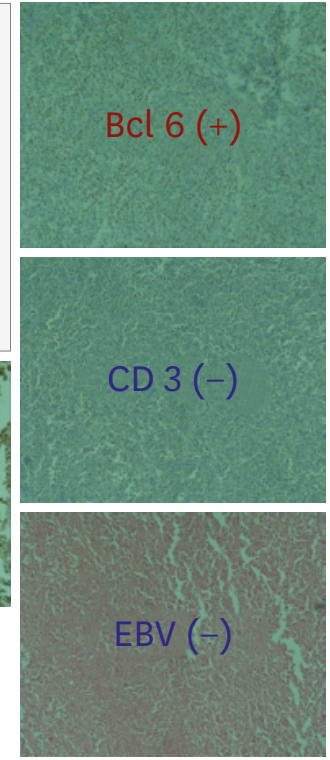

Figure 4. Anterior mediastinal lymph node excision biopsy showed a malignant large B cell lymphoma. $\mathrm{BCl}=\mathrm{B}$-cell lymphoma; $\mathrm{CD}=$ cluster of differentiation; $\mathrm{EBV}=$ Epstein-Barr virus.

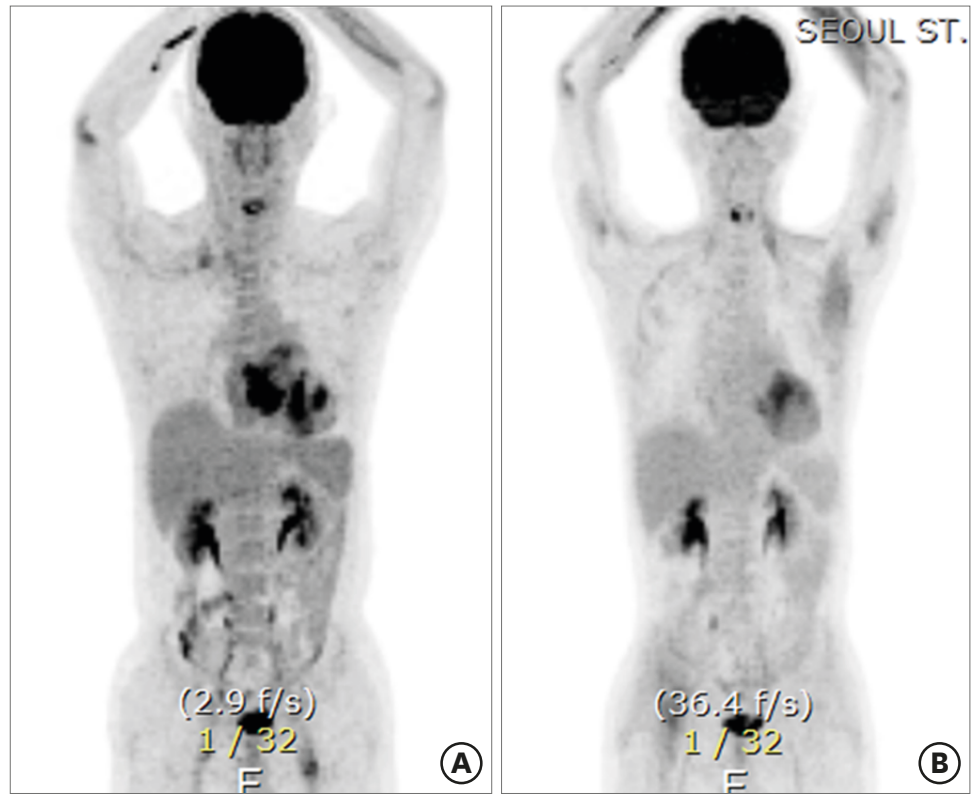

Figure 5. Images of positron emission tomography-computed tomography. (A) In the 7th year after the first visit, intense focal FDG uptakes were observed in the LA and LV wall. (B) Six months after starting rituximab, cyclophosphamide, doxorubicin, vincristine, and prednisolone chemotherapy, the FDG uptake in the LV wall decreased significantly.

FDG = fluoro-deolyglucose; $L A=$ left atrial; LV = left ventricular

\section{REFERENCES}

1. Jeudy J, Kirsch J, Tavora F, et al. From the radiologic pathology archives: cardiac lymphoma: radiologicpathologic correlation. Radiographics 2012;32:1369-80.

PUBMED | CROSSREF 
2. Mendelson L, Hsu E, Chung H, Hsu A. Primary cardiac lymphoma: importance of tissue diagnosis. Case Rep Hematol 2018:6192452. CROSSREF

3. Petrich A, Cho SI, Billett H. Primary cardiac lymphoma: an analysis of presentation, treatment, and outcome patterns. Cancer 2011;117:581-9.

PUBMED | CROSSREF

4. Tai CJ, Wang WS, Chung MT, et al. Complete atrio-ventricular block as a major clinical presentation of the primary cardiac lymphoma: a case report. Jpn J Clin Oncol 2001;31:217-20.

PUBMED | CROSSREF 